\title{
PLACEMENT GRIDS, POROSITY AND RANDOMNESS OF ARMOR LAYERS
}

\author{
Vicente Pardo ${ }^{1}$, Maria Piedad Herrera ${ }^{1}$, Jorge Molines ${ }^{1}$ and Josep Ramon Medina ${ }^{1}$
}

\begin{abstract}
Armor porosity and armor unit randomness are much easier to control in small-scale models constructed by hand than in prototype. Differences between design and prototype armor porosities and design and armor unit randomness can generate significant model effects. This paper describes realistic 3D placement tests with cube and Cubipod CAUs, using a small-scale crawler crane and pressure clamps. This research aims to estimate workable armor porosities at prototype scale and to determine the prototype placement grids to obtain the armor porosities commonly tested in laboratories. A new methodology based on laser scanning was developed to measure armor unit randomness. This methodology can be applied to both small-scale models and prototypes. Armor Randomness Indexes (ARIs) are proposed to measure the randomness of cube and Cubipod armor units. The ARI values were higher for Cubipods than for cubes.
\end{abstract}

Keywords: breakwater; armor unit; armor porosity; placement grid; Cubipod; random placement; randomness.

\section{INTRODUCTION}

Mound breakwaters are used worldwide to protect port areas from wave action. As maritime transportation and shipping have increased dramatically over the last two centuries, breakwater dimensions have also increased, and thus larger stones are needed to built armor layers. Cube and parallelepiped concrete armor units (CAUs) appeared in the $19^{\text {th }}$ century when local quarries could not provide the appropriate quarry stones. Since the mid-20th century, many types of CAU have been designed to optimize breakwaters, giving more stability and reducing construction and maintenance costs. CAUs can be grouped depending on relative structural strength: massive, bulky and slender.

Massive conventional cubes are the most commonly used CAUs in Spain because they are easy to manufacture, stack and handle. Additionally, cube CAUs have a high structural strength and a low risk of progressive failure. However, cubic blocks have disadvantages like low hydraulic stability $\left(\mathrm{K}_{\mathrm{D}}=6\right)$ and high heterogeneous packing (face-to-face fitting, high overtopping and low friction with filter layer). Gómez-Martín and Medina (2008) designed the Cubipod, a massive CAU that presents the advantages of the cubic block but improves its drawbacks. The Cubipod has a high hydraulic stability coefficient $\left(\mathrm{K}_{\mathrm{D}}=12\right.$ for single-layer and $\mathrm{K}_{\mathrm{D}}=28$ for double-layer), a high friction factor which reduces overtopping rates, low heterogeneous packing rates and greater friction with the filter layer. Fig. 1 shows a 16-tonne Cubipod handled with pressure clamps.

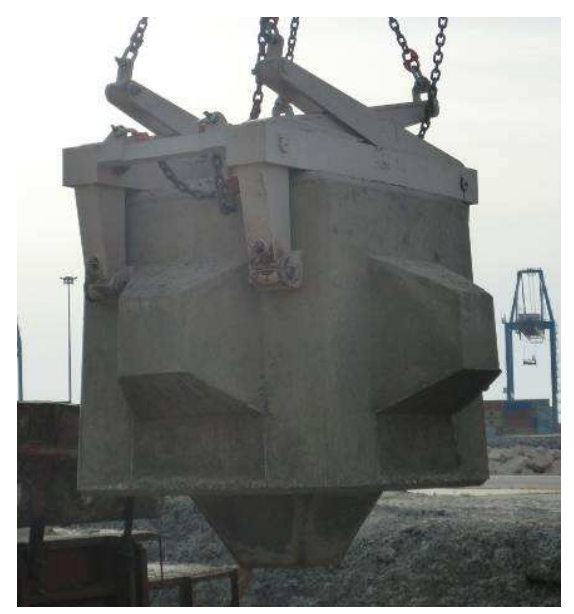

Figure 1. Cubipod CAU handled with pressure clamps.

Engineering manuals generally provide tables which define recommended armor porosity and placing density values for each type of CAU. To minimize model effects, armor porosity should be the same in small-scale laboratory tests and in the corresponding prototypes. Unlike small-scale laboratory models, breakwater armor construction at prototype scale is highly dependent on wind and waves

\footnotetext{
${ }^{1}$ Laboratory of Ports and Coasts, Universitat Politècnica de València, Camino de Vera s/n, Valencia, 46021, Spain
} 
climates, underwater visibility and the equipment available (crawler cranes with pressure clamps or slings). The breakwater armor construction must consider such different conditions to avoid significant model effects. Because CAU hydraulic stability is directly related to armor porosity and placement pattern (see Frens, 2007 and Medina et al., 2010), a model effect arising from differences in armor porosity and placement may significantly increase the risk of failure. Armor porosity and placement patterns affect not only hydraulic stability but also wave reflection, run-up and overtopping. In the design phase, armor porosity must be defined in order to estimate the volume of materials and concrete needed to construct the armor layer; therefore, a deviation in armor porosity during construction may result in significant model effects and logistic problems.

It is widely accepted that CAUs can be placed uniformly, patterned, oriented or randomly. Uniformed and patterned placements are carefully designed and executed; however, it is not clear what constitutes "random placement" (see Medina et al., 2011). Generally speaking, random placement is assumed if the crane operator does not try to place each CAU with a specific orientation.

In this paper, armor porosity, placement grids and armor unit randomness of cube and Cubipod CAUs were analyzed. Realistic 3D placement tests were carried out with cube and Cubipod CAUs, using a small-scale crawler crane and pressure clamps under moderate wave attack. The Punta Langosteira breakwater model was studied to obtain the workable armor porosities at prototype scale and to determine the optimum geometric characteristics of the placement grids needed to obtain the armor porosities usually tested in laboratory, $\mathrm{p} \%=37 \%$ for cube armors and $\mathrm{p} \%=42 \%$ for Cubipod armors. Moreover, the prototype placement grid used in the Punta Langosteira breakwater, armored with 150-tonne cubic blocks, was analyzed in realistic 3D construction tests. In order to quantify the randomness of cube and Cubipod CAUs in armor layers, the new methodology proposed by Medina et al. (2011) was followed. Three Armor Randomness Indexes (ARIs) are used: $\mathrm{ARI}_{0}$ to measure the spatial orientation of each armor unit in relation to the armor slope plane; $\mathrm{ARI}_{1}$ and $\mathrm{ARI}_{2}$ to measure the relative orientation of the $\mathrm{CAU}$ in relation to the first and second closest CAU, respectively, within the armor.

\section{ARMOR POROSITY}

Porosity refers to the percentage of voids in a granular system. Porosity is generally considered during the design and construction stages of mound breakwaters; however, armor porosity is difficult to quantify. In order to estimate armor porosity, armor thickness must first be defined, which is not easy for randomly placed CAUs. The armor thickness is commonly assumed to be the number of layers multiplied by the equivalent cube size or nominal diameter $\left(D_{n}\right)$, which is the cubic root of the CAU volume.

Like most engineering manuals, the SPM (1984) recommended specific nominal armor porosities $(\mathrm{P} \%)$ for the different CAUs associated with a given layer coefficient $\left(\mathrm{k}_{\Delta}\right)$, which is an armor thickness corrector. The placing density $\left(\varphi\left[\right.\right.$ units $\left.\left./ \mathrm{m}^{2}\right]\right)$ is the only parameter which can be controlled during construction and it is related to both nominal porosity $(\mathrm{P} \%)$ and layer coefficient $\left(\mathrm{k}_{\Delta}\right)$ according to Eq. 1 (see SPM, 1984).

$$
\varphi=\frac{N_{a}}{A}=n\left(k_{\Delta}\right)(1-P \%)\left(\frac{\gamma_{r}}{W}\right)^{2 / 3}
$$

where $\mathrm{N}_{\mathrm{a}}=$ number of armor units placed on the surface $A ; \mathrm{n}=$ number of layers of CAUs; $\mathrm{k}_{\Delta}=$ layer coefficient; $\mathrm{P} \%=$ nominal armor porosity, and $\mathrm{W} / \gamma_{\mathrm{r}}=$ volume of CAU. The packing density $(\Phi)$, see Eq. 2, is also used to measure the relative consumption of concrete in the armor layer. The packing density $(\Phi)$ can be considered the dimensionless placing density using the equivalent cube size.

$$
\Phi=n\left(k_{\Delta}\right)(1-P \%)
$$

Regarding the placing density, different pairs of nominal porosity and layer coefficient $\left(\mathrm{P} \%, \mathrm{k}_{\Delta}\right)$ may lead to the same value for $\varphi$. For example, a nominal porosity of $\mathrm{P} \%=47 \%$ with a layer coefficient of $\mathrm{k}_{\Delta}=1.10$ is comparable to an armor porosity of $\mathrm{p} \%=42 \%$ with a layer coefficient of $\mathrm{k}_{\Delta}=1.00$. The different criteria used by different authors to define the layer coefficient have naturally lead to misunderstandings (Frens, 2007).

In this paper the criteria given by Medina et al. (2010) is applied as being valid for randomlyplaced CAUs: the armor porosity, $\mathrm{p} \%=(1-\Phi / \mathrm{n})$, is the porosity associated to a layer coefficient of $\mathrm{k}_{\Delta}=$ 
1.00 , and the armor thickness is one or two times the equivalent cube size for single-layer or doublelayer armors.

As armor porosity directly affects breakwater performance and hydraulic stability (Van der Meer, 1999; Yagci and Kapdasli, 2003; Bakker et al., 2005) differences between design and prototype values may lead to significant risk. Small-scale experiments are rarely conducted considering different porosities. Moreover, armor porosity is crucial during construction, because it is directly related to the necessary volume of materials (concrete consumption) and hence construction costs.

\section{RANDOMNESS OF ARMOR LAYERS}

\section{Armor Unit Randomness}

CAUs can be uniformly, patterned, oriented or randomly placed (Dupray and Roberts, 2009). The first three placement systems are usually well defined in the literature, but random placement is not. Cubic blocks, Cubipods, Tetrapods and other CAUs are designed to be placed randomly, but no measurement of randomness is given for small-scale models or prototype scale. Armors are frequently constructed using crawler cranes equipped with pressure clamps or slings to place the CAUs according to the coordinates given by the placement grid. "Random placement" is commonly assumed if the crane operator does not try to place each unit in a specific orientation in relation with its neighboring units. During cube armor construction the crane operator tries to favor randomness (above MWL) by preventing the cubes from having one face parallel to the slope plane as well as avoiding face-to-face fitting between neighboring CAUs.

Armor unit randomness may affect the breakwater performance: the hydraulic stability can change and the overtopping rates increase in poor randomly-placed cube armors. Furthermore, armor unit randomness is easily achieved under ideal conditions in small-scale models with placement by hand; however, at prototype scale CAUs are placed with crawler cranes, so armor randomness is quite difficult to control because of environmental conditions (underwater viewing conditions, waves and wind).

In this paper, a new methodology is proposed to measure armor unit randomness. Perfect armor randomness is not possible because the CAU geometry favors self-organization on the slope, which tends to reduce armor unit randomness. For example, cube units placed randomly on a breakwater slope tend to face parallel to the slope and fit face-to-face with neighboring cubes. Thus, some breakwater armors appear to be more randomly placed than others. Two aspects should be considered when measuring for randomness: the orientations of a CAU in relation to the breakwater underlayer slope plane and its relative position with neighboring CAUs. This paper focuses on the case of cubic blocks and Cubipods, which feature three orthogonal planes of symmetry. Cube and Cubipod orientations in the space can be directly related to these three orthogonal planes which are parallel to the cube and Cubipod faces.

\section{Armor Randomness Indexes}

In order to quantify the randomness of cube and Cubipod CAUs in armor layers, the three Armor Randomness Indexes (ARIs) proposed by Medina et al. (2010) were considered: $\mathrm{ARI}_{0}$, which measures the spatial orientation of each armor unit in relation to the armor slope plane; $\mathrm{ARI}_{1}$, which measures the relative orientation of a CAU and the first closest CAU within the armor; and $\mathrm{ARI}_{2}$, which measures the relative orientation of a $\mathrm{CAU}$ and the second closest $\mathrm{CAU}$ within the armor. $\mathrm{ARI}_{1}$ and $\mathrm{ARI}_{2}$ serve to evaluate the face-to-face disposition around a given CAU. ARIs are calculated from particular angles between cube and Cubipod faces and the slope plane and the neighboring CAU faces.

For each CAU placed in the armor layer, $\alpha$ is defined as the minimum angle between the three orthogonal vectors of each unit's faces and the breakwater underlayer slope plane orthogonal vector. For randomly-placed CAUs, the $\alpha$ value range is $0^{\circ} \leq \alpha \leq 54.73^{\circ}$. Fig. 2 illustrates $\alpha=51^{\circ}$ between a Cubipod and the slope plane orthogonal vector. If $\alpha=0$, all the points of one face are resting on the slope. 


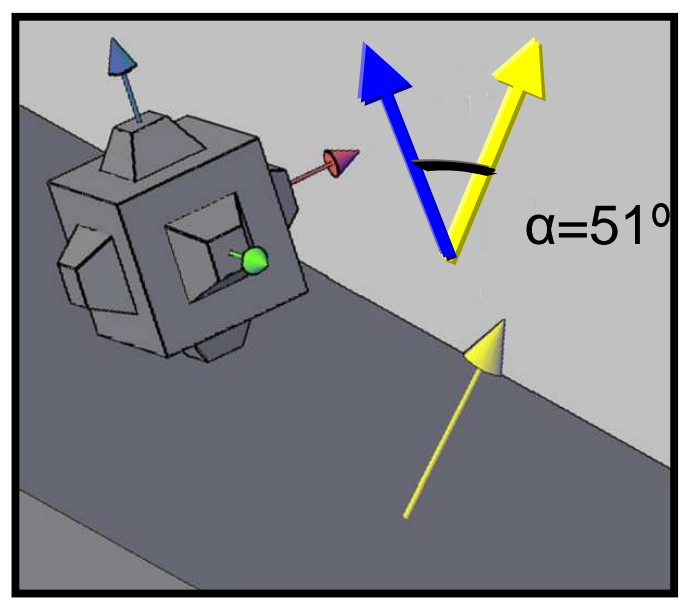

Figure 2. Example of $\alpha=51^{\circ}$ between a Cubipod CAU and the breakwater slope plane vector.

Using numerical simulations, one million cubes were randomly oriented in the space to estimate the cumulative distribution function of $\alpha \mathrm{F}_{0}(\alpha)$ for randomly-oriented units. The $10 \%, 50 \%$ and $90 \%$ percentiles of $\alpha$ were used to characterize this function. Fig. 3 shows the three percentiles of the random distribution function $F_{0}(\alpha)$ and the empirical distribution function $F(\alpha)$ used to calculate the $\mathrm{ARI}_{0}$ for one case of cube armor. If the analyzed CAUs are randomly placed, $\mathrm{F}(\alpha)$ should be similar to $F_{0}(\alpha)$ and the ratios between percentiles should be around 1.0. The data in Fig. 3 suggest that cube armor orientation differs from real random placement.

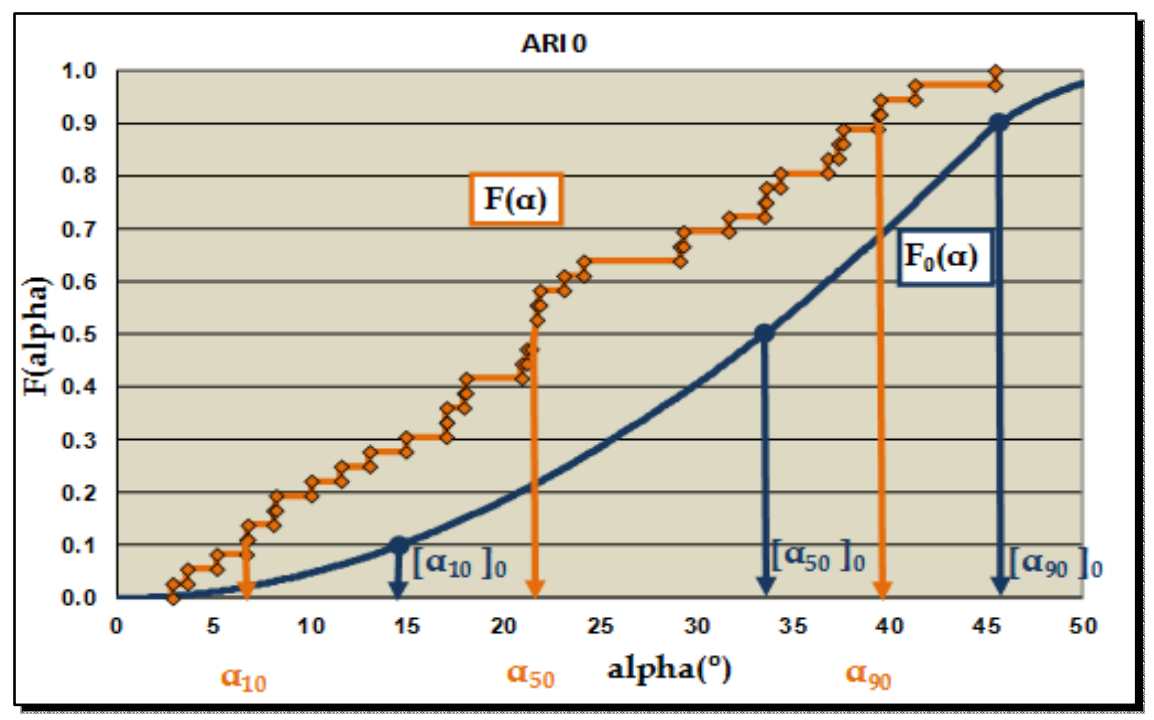

Figure 3. Random distribution function $F_{0}(\alpha)$ and empirical distribution function $F(\alpha)$ used to calculate the $\mathrm{ARI}_{0}$ for one case of cube armor.

For CAUs placed on breakwater armor layer, the $\mathrm{ARI}_{0}$ is defined as the average of ratios, not higher than one, between the $10 \%, 50 \%$ and $90 \%$ percentiles $\left(\alpha_{10}, \alpha_{50}, \alpha_{90}\right)$ of the empirical distribution function $\mathrm{F}(\alpha)$ and the corresponding percentiles of $\mathrm{F}_{0}(\alpha)$. See Eq. 3.

$$
A R I_{0}=\frac{\left(\left[\min \left(1.0, \frac{\alpha_{10}}{\left[\alpha_{10}\right]_{0}}\right)\right]+\left[\min \left(1.0, \frac{\alpha_{50}}{\left[\alpha_{50}\right]_{0}}\right)\right]+\left[\min \left(1.0, \frac{\alpha_{90}}{\left[\alpha_{90}\right]_{0}}\right)\right]\right)}{3}
$$

If $\mathrm{ARI}_{0}$ is close to $100 \%$, the CAUs will be randomly placed. If $\mathrm{ARI}_{0}$ is close to $0 \%$, all the CAUs will be placed with one face parallel to the underlayer slope plane. In accordance with this criterion, the lower the $\mathrm{ARI}_{0}$, the poorer the armor randomness. 
To quantify the randomness of a given armor unit in relation to the first and second closest neighboring $\mathrm{CAU}$, for each orthogonal face of the unit, the $\beta_{\mathrm{i}}(\mathrm{i}=1,2$ and 3 ) angle is defined as the minimum of the three angles between face $i$ of one unit and the three orthogonal faces of the neighboring unit. The $\beta$ angle between two units placed on the armor layer is defined as the average of the $\beta_{\mathrm{i}}$ angles of the three orthogonal faces of the unit, $\beta=(\beta 1+\beta 2+\beta 3) / 3$. The maximum $\beta_{\mathrm{i}}$ for randomlyplaced CAUs is $54.7^{\circ}$ while the maximum $\beta$ is $47.9^{\circ}$; therefore, $0^{\circ} \leq \beta \mathrm{i} \leq 54.7^{\circ}$ and $0^{\circ} \leq \beta \leq 47.9^{\circ}$. Fig. 4 provides an example of $\beta$ calculation between two neighboring cube CAUs.

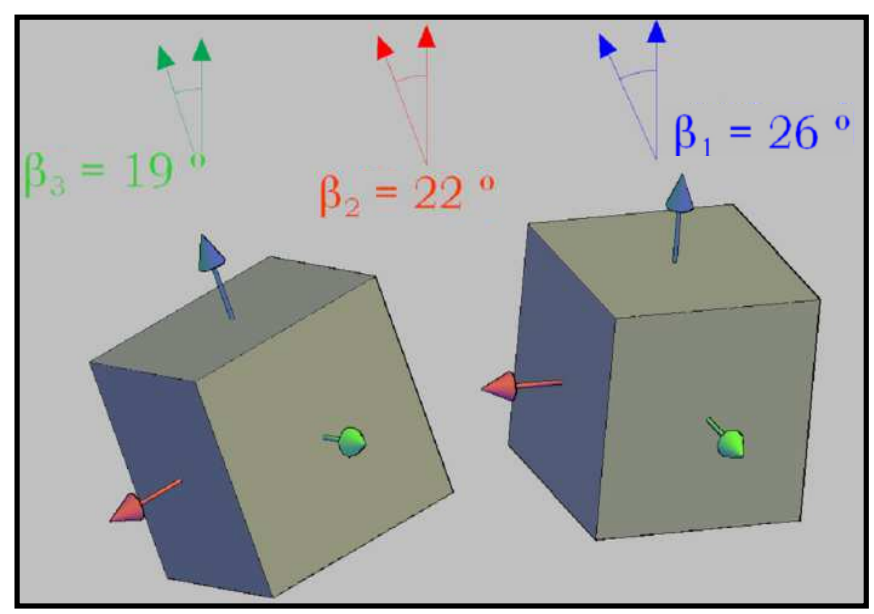

Figure 4. Example of $\beta$ calculation between neighboring cube CAUs.

Using numerical simulation, one million pairs of cubes were randomly oriented in the space and the cumulative distribution function of $\beta, \mathrm{F}_{0}(\beta)$, was estimated. The $10 \%, 50 \%$ and $90 \%$ percentiles of $\beta$ were used to characterize this function. Fig. 5 shows the three percentiles of the random distribution function $\mathrm{F}_{0}(\beta)$ and the empirical distribution function $\mathrm{F}(\beta)$ used to calculate the $\mathrm{ARI}_{1}$ for one case of cube armor.

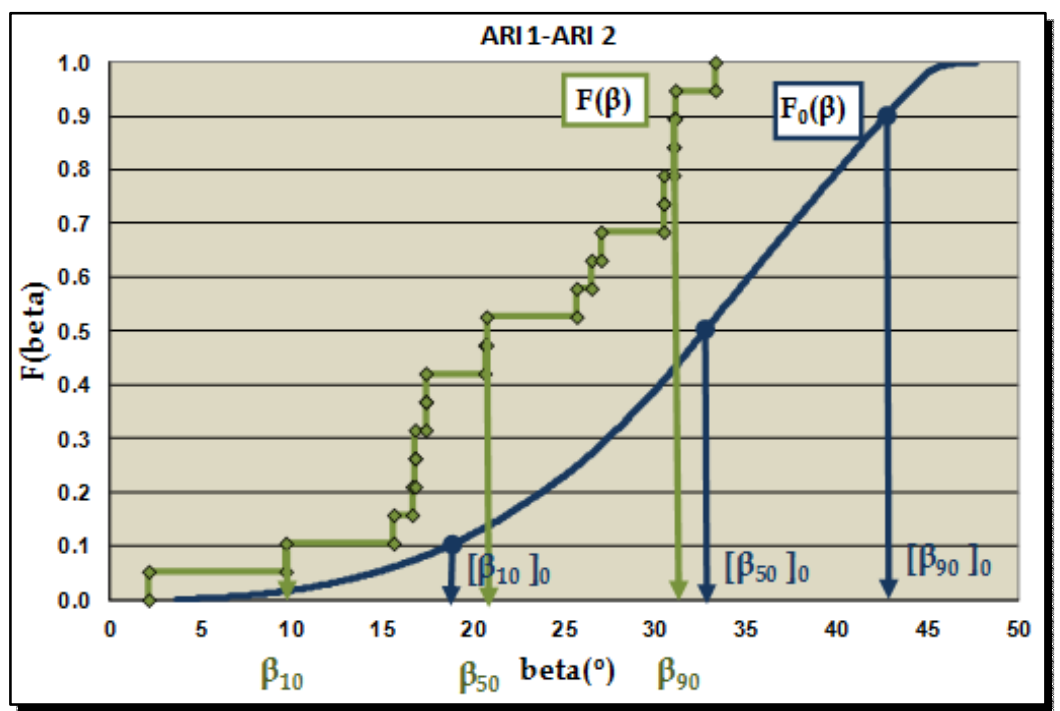

Figure 5. Random distribution function $F_{0}(\beta)$ and empirical distribution function $F(\beta)$ used to calculate the $A R I_{1}$ for one case of cube armor.

For a given group of CAUs placed on breakwater armor layer, each unit in the group was compared to the two closest units in the group; the first was used to estimate the $\mathrm{ARI}_{1}$ and the second, $\mathrm{ARI}_{2}$. The $\beta$ angle was calculated for each pair of CAUs. Like $\mathrm{ARI}_{0}, \mathrm{ARI}_{1}$ and $\mathrm{ARI}_{2}$ are defined as the average of ratios, not higher than one, between the $10 \%, 50 \%$ and $90 \%$ percentiles $\left(\beta_{10}, \beta_{50}, \beta_{90}\right)$ of the empirical distribution function $F(\beta)$ and the corresponding percentiles of $F_{0}(\beta)$. See Eq. 4. 
$A R I_{1}$ and $A R I_{2}=\frac{\left(\left[\min \left(1.0, \frac{\beta_{10}}{\left[\beta_{10}\right]_{0}}\right)\right]+\left[\min \left(1.0, \frac{\beta_{50}}{\left[\beta_{50}\right]_{0}}\right)\right]+\left[\min \left(1.0, \frac{\beta_{90}}{\left[\beta_{90}\right]_{0}}\right)\right]\right)}{3}$

If $\mathrm{ARI}_{1}$ and $\mathrm{ARI}_{2}$ are close to $100 \%$, the group of CAUs is randomly oriented. If $\mathrm{ARI}_{1}$ and $\mathrm{ARI}_{2}$ are close to $0 \%$, the three orthogonal faces of each CAU face the others in a perfectly ordered pattern. According to this criterion, the lower the $\mathrm{ARI}_{1}$ and $\mathrm{ARI}_{2}$, the poorer the armor randomness.

\section{EXPERIMENTAL METHODOLOGY}

\section{D placement test}

The construction of small-scale armor layers differs considerably from prototype scale. While small-scale models are usually built in ideal conditions (perfect view, no water and construction by hand), prototype scale armor layers are highly restricted by environmental conditions (blind placement, waves, wind) and equipment availability (machinery and handling). Therefore, it is relatively easy to construct low porosity randomly-placed cube armors in a laboratory. As low armor porosity is more stable and has more reflection and overtopping than high porosity armors, a model effect can thus be expected.

In order to estimate workable armor porosities at prototype scale and based on the methodology described by Medina et al. (2010) and Pardo et al. (2010), realistic 3D placement tests were designed to emulate prototype armor construction with cube and Cubipod CAUs. The tests were carried out at the UPV wave basin using a small-scale crawler crane and pressure clamps (see Fig. 6). The armor layer of the Punta Langosteira breakwater model $(1 / 100)$ was constructed with a slope $H / V=2 / 1$, an underlayer of a conventional double layer cube armor of $\mathrm{W}[\mathrm{t}]=15$, cube CAUs of $\mathrm{W}[\mathrm{t}]=150$ for the main layer and with wave characteristics of spring-summer $(\mathrm{Hs}[\mathrm{m}]) 1.5$ and $2.5 ; \mathrm{Tp}[\mathrm{s}] 10$ and 12).
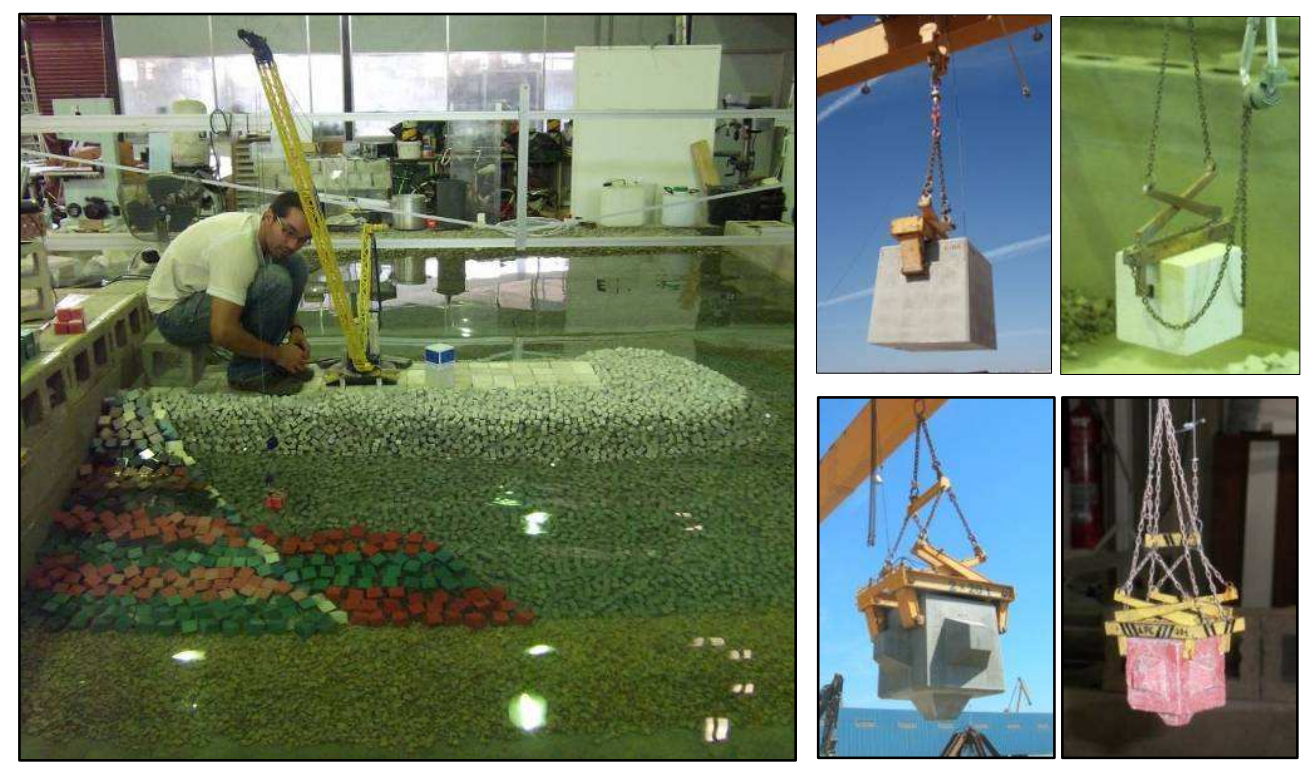

Figure 6. 3D placement test, small-scale crawler crane and pressure clamps.

Two placement grids were tested during the 3D placement tests: a conventional fixed diamondshape grid, and a progressive diamond-shape grid. In the latter, the distances between rows decreased progressively with the construction to account for row packing. Fig. 7 shows the schema of the fixed and progressive grids. 

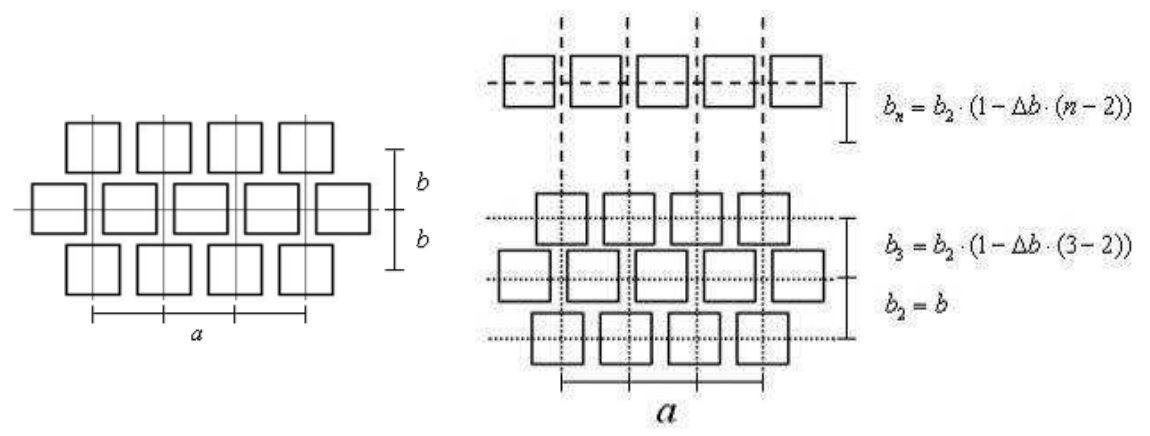

Figure 7. Schema of the fixed diamond-shape grid (left) and the progressive diamond-shape grid (right).

The parameter $a$ is the distance between two CAU centers of mass in the breakwater-trunk direction; $b$ is the distance between two CAU centers of mass in the toe-crown direction; $b_{i}\left(b_{i}=\mathrm{b}_{2}\right.$ [1$\Delta \mathrm{b}(\mathrm{i}-2)])$ is the distance between CAU centers of mass in rows $\mathrm{i}$ and $\mathrm{i}-1 \quad(\mathrm{i}=2,3, \ldots \mathrm{n}) ; \Delta b$ is the $b$ decrease to implement the row packing; and $n$ is the number of rows.

After each armor layer construction test, the real armor porosity was obtained using a mobile area (see Fig. 8) positioned in 21 locations to prevent the border effect in the porosity estimation. The real armor porosity was calculated as: $\mathrm{P}_{\text {real }}=1-\left[\left(\mathrm{N}_{\mathrm{r}} \mathrm{D}_{\mathrm{n}}{ }^{2}\right) / \mathrm{A}\right]$; where $N_{r}$ is the average of units in the reference area; $D_{n}$ is the nominal diameter or the equivalent cube size, and $A$ is the value of the reference area.

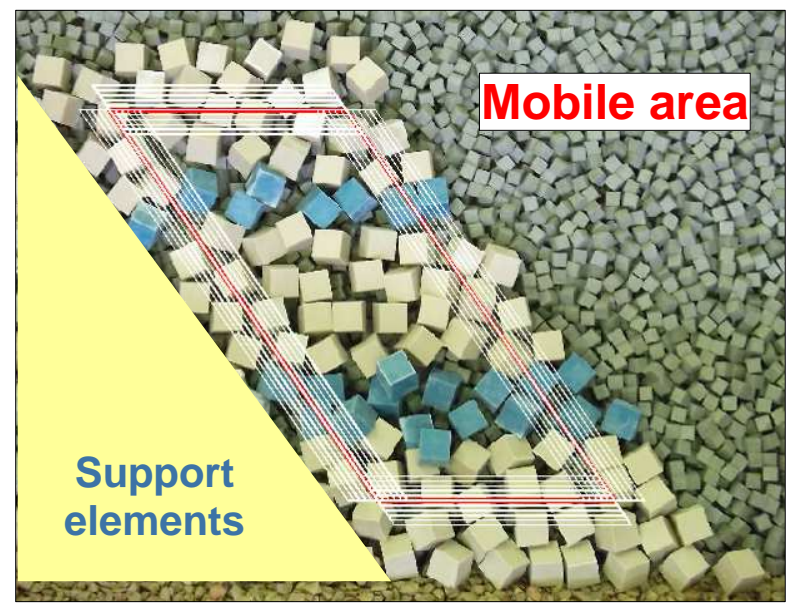

Figure 8. Image of mobile area used to calculate armor porosity.

To reduce the time needed for the tests (1 minute/unit), a Cartesian Blind Placement System (CBPS) was used to estimate the minimum and maximum armor porosity achieved in real construction. Even though underwater placement was blind, the waves did not affect placement; thus the actual placement was more realistic than that commonly done by hand in small-scale experiments, but not as realistic as placement using small-scale crawler cranes. The CBPS reduced the time spent for each unit to 10 seconds. Fig. 9 provides views of the CBPS and the clamp operator releasing a unit on to the slope. 


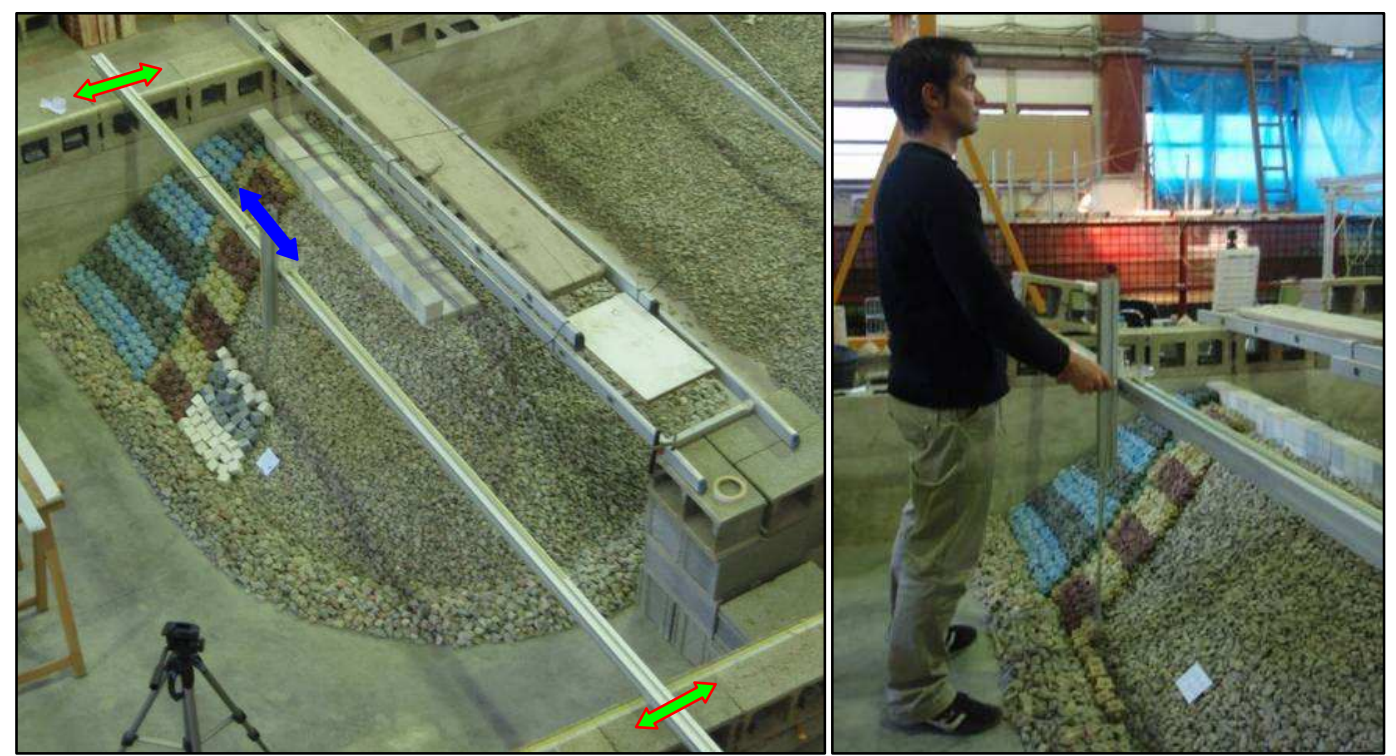

Figure 9. Views of Cartesian Blind Placement System (left) and clamp operator (right).

The armor layer was visually appraised after each placement test and this was used as a qualitative criterion to discriminate between acceptable and unacceptable armor layer construction. For the Cubipod armor the workable porosities ranged from $37 \%$ to $51 \%$ compared to $35 \%$ to $45 \%$ for the cube armor. By contrast, small-scale laboratory experiments generally consider porosities of $42 \%$ for Cubipods and $37 \%$ for cubes.

After estimating the workable porosity range for prototype scale, the systematic $3 \mathrm{D}$ placement tests were carried out using a small-scale crawler crane (1/100), (LIEBHERR LR 11350 model) equipped with pressure clamps (see Fig. 6). Fist, different grids were tested with Cubipods to obtain a real porosity close to that tested in small-scale models (around 42\%). It was the progressive grid $\left(a / D_{n}=\right.$ $1.60, b / D_{n}=1.17$ and $\Delta b=1 \%$ b) which provided armor porosity of $42.2 \%$ for the first layer and $40.4 \%$ for the second. Both values were quite close to the $42 \%$ tested in small-scale models. Second, using cubes, the Langosteira breakwater real placement grid was tested; it provided a real porosity of $44,9 \%$, just under the target porosity, $45 \%$. But this value was far higher than the $37 \%$ commonly used in small-scale tests. Therefore, a final test aimed to obtain a real armor porosity similar to that used in the laboratory. After testing the grids, it was the fixed grid $a / D_{n}=1.44$ and $b / D_{n}=1.19$, which provided an armor porosity of $35.2 \%$ for the first layer and $38.5 \%$ for the second. Fig. 10 shows the 3D placement for the first layer of Cubipod and cube armors.
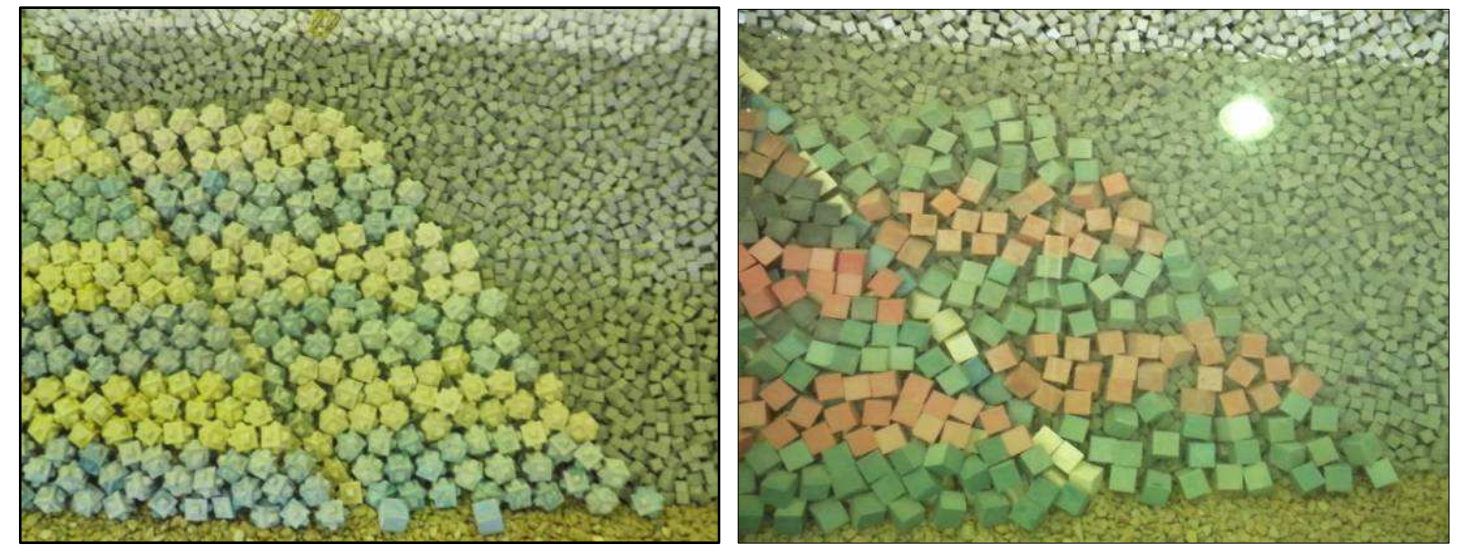

Figure 10. 3D placement for the first layer of Cubipod (left) and cube (right) armors. 


\section{Laser scanning process}

To measure armor unit randomness after each 3D placement test, a short-range high-precision $(1 \mathrm{~mm})$ laser scanner was used to scan cube and Cubipod armors (nominal diameter of $40 \mathrm{~mm}$ and 38 $\mathrm{mm}$, respectively). Fig. 11 shows images from the laser scanning process.
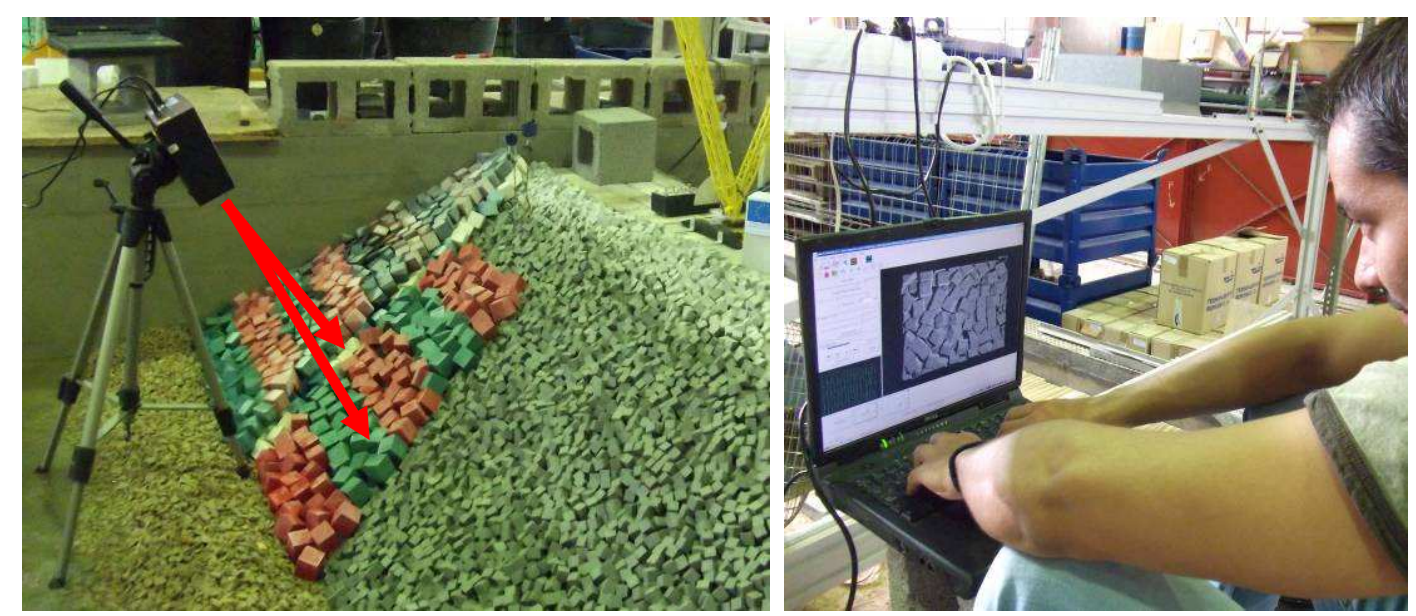

Figure 11. Laser scanning process.

The scanner raw data (shown in Fig. 12) were processed to determine the position and orientation of each armor unit placed on the breakwater slope. The aims were to calculate the ARIs and to measure the randomness of each armor unit.
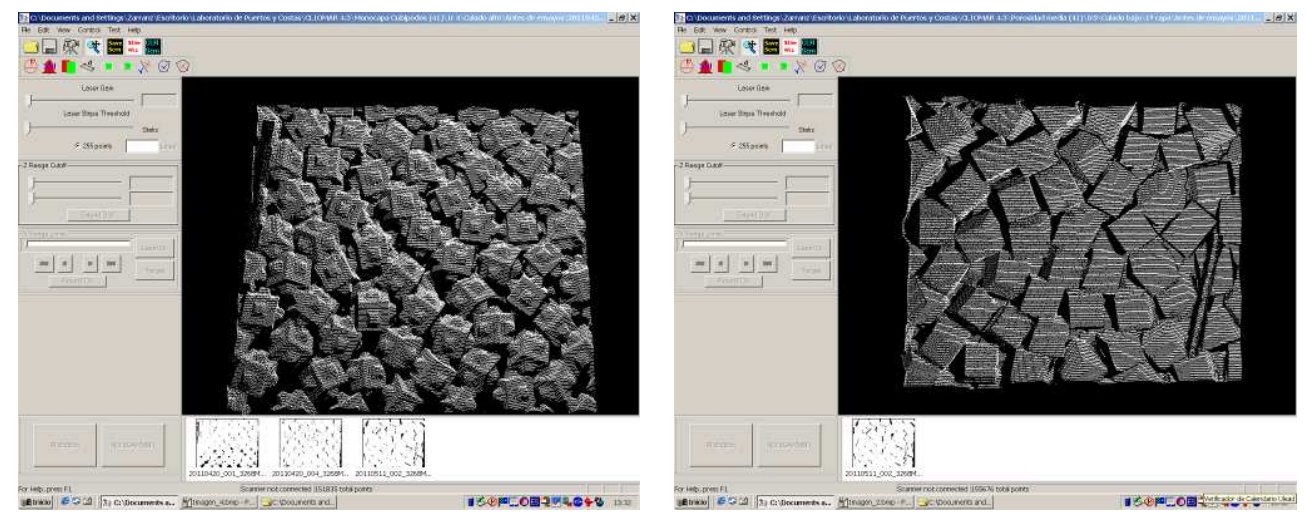

Figure 12. Cubipod (left) and cube (right) laser scanner (raw data).

The graphs in Figure 13 plot the measured ARIs for each armor layer constructed in the 3D placement tests, the blue lines marking values for Cubipod armors and red, for cube armors. The average $\mathrm{ARI}$ values for Cubipod armors are $\mathrm{ARI}_{0}=93 \%, \mathrm{ARI}_{1}=74 \%$ and $\mathrm{ARI}_{2}=82 \%$, and for cube armors, $\mathrm{ARI}_{0}=67 \%, \mathrm{ARI}_{1}=60 \%$ and $\mathrm{ARI}_{2}=70 \%$. Thus, armor unit randomness for Cubipod was higher than for cube armors when placed randomly using a crawler cranes and pressure clamps under moderate wave attack. Furthermore, the $\mathrm{ARI}_{1}$ and $\mathrm{ARI}_{2}$ results suggest that the proximity of neighboring CAUs affects armor unit randomness. 

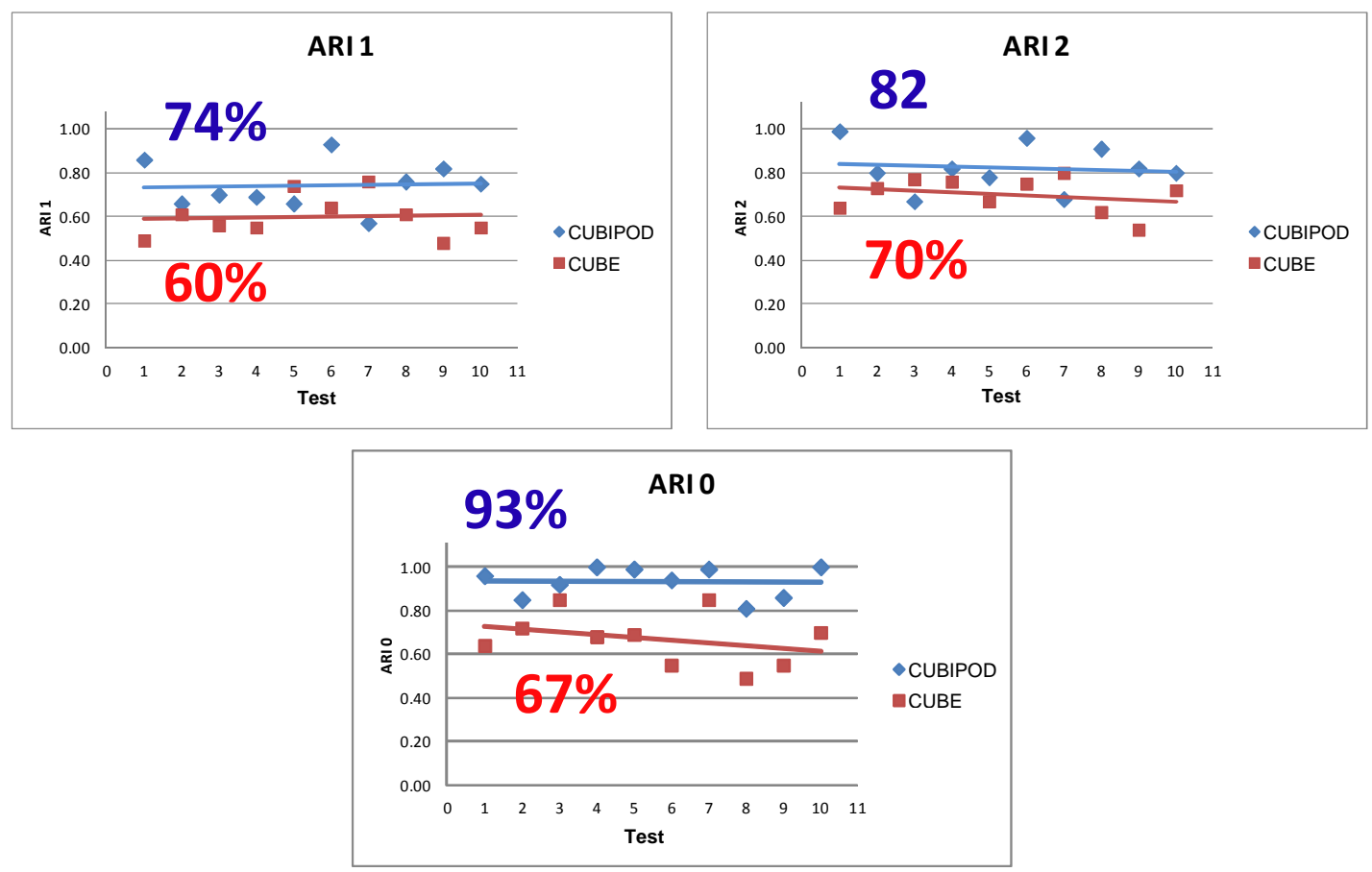

Figure 13. Measured ARIs of armor layers constructed in 3D placement tests.

\section{SUMMARY AND CONCLUSIONS}

Usually, armor porosity and armor unit randomness pass unnoticed when testing randomly-placed CAUs. Armor porosity and armor unit randomness are easy to control in small-scale models constructed by hand but difficult to control at prototype scale. Differences between design and prototype armor porosities or armor unit randomness generate significant model effects. Armor porosity, placement and armor unit randomness of cube and Cubipod CAUs were analyzed in this paper. Both are massive, randomly-placed CAUs which can be safely handled using pressure clamps.

For randomly-placed CAUs, the armor porosity is difficult to quantify. Most engineering manuals recommend a specific nominal armor porosity (P\%) for a particular CAU associated to a given layer coefficient $\left(\mathrm{k}_{\Delta}\right)$. This has caused some misunderstandings in engineering communication because of the different criteria used. To avoid confusion, in this paper the criterion given by Medina et al. (2010) is considered as valid for randomly-placed CAUs: the armor porosity, $\mathrm{p} \%=(1-\Phi / \mathrm{n})$ is the porosity associated to a layer coefficient of $\mathrm{k}_{\Delta}=1.00$, and the armor thickness is one or two times the equivalent cube size for single-layer or double-layer armors.

Realistic 3D placement tests with cube and Cubidod CAUs were carried out based on the Punta Langosteira breakwater model (slope $\mathrm{H} / \mathrm{V}=2 / 1$ ). Workable armor porosities at prototype scale were obtained as were placement grids that provided a real armor porosity similar to that tested in the smallscale physical models (near $42 \%$ for Cubipod and $37 \%$ for cube armors). In these tests a new grid type was designed, the progressive diamond-shape grid, which considers the row packing. In the case of Cubipod armors, a progressive placement grid with parameters $a / D_{n}=1.60, b / D_{n}=1.17$ and $\Delta b=1 \%$ b, provided armor porosities of $42.2 \%$ and $40.4 \%$ for the first and the second layer, respectively. For cube armors, a fixed grid with parameters $a / D_{n}=1.44$ and $b / D_{n}=1.19$, provided armor porosities of $35.2 \%$ for the first layer and $38.5 \%$ for the second.

This study also developed a new methodology to measure armor unit randomness based on laser scanning of small-scale models and prototypes. Three Armor Randomness Indexes (ARIs) are proposed: $\mathrm{ARI}_{0}$ to measure the spatial orientation of each CAU in relation to the armor slope plane; $A R I_{1}$ to measure the relative orientation of the CAU and the first closest CAU within the armor; and $\mathrm{ARI}_{2}$ to measure the relative orientation of the CAU and the second closest CAU within the armor. The ARIs are calculated from angles between cube and Cubipod faces and the slope plane and the neighboring CAU faces. The average ARI values for Cubipod armors are $\mathrm{ARI}_{0}=93 \% ; \mathrm{ARI}_{1}=74 \%$ and $\mathrm{ARI}_{2}=82 \%$, and those for cube armors are $\mathrm{ARI}_{0}=67 \% ; \mathrm{ARI}_{1}=60 \%$ and $\mathrm{ARI}_{2}=70 \%$. The measurements indicate that armor unit randomness was higher for Cubipod than cube armors when placed randomly using crawler cranes and pressure clamps. 
Both armor porosity and armor unit randomness directly affect breakwater performance and construction costs. Therefore these two parameters must be measured for randomly-placed CAUs in small-scale models and monitored closely at prototype scale these two characteristics.

\section{ACKNOWLEDGMENTS}

The authors received financial support from CDTI (CUBIPOD Project). The authors thank Tomás Pérez for assisting with the 3D placement tests and for processing the laser scanner, and Debra Westall for revising the manuscript.

\section{REFERENCES}

Bakker, P., M. Klabbers, M. Muttray, and A. van den Berge. 2005. Hydraulic performance of Xbloc armour units. Proc. $1^{\text {st }}$ International Conference on Coastal Zone Management and Engineering in the Middle East.

Dupray, S., and J. Roberts. 2009. Review of the use of concrete in the manufacture of concrete armour units. Proc. of Coasts, Marine Structures and Breakwaters 2009, Thomas Telford Ltd., Vol. 1, 245-259.

Frens, A.B. 2007. The impact of placement method on Antifer-block stability. M.Sc. thesis, Delft University of Technology.

Gómez-Martín, M.E. and J.R. Medina. 2008. Erosion of cube and Cubipod armour layers under wave attack. Proc. $30^{\text {th }}$ International Conference on Coastal Engineering, ASCE, 3461-3473.

Medina, J.R., M.E. Gómez-Martín, and A. Corredor. 2010. Influence of armor unit placement on armor porosity and hydraulic stability. Proc. $32^{\text {nd }}$ International Conference on Coastal Engineering, ASCE, Paper No. 255/structures.41.

Medina, J.R., M.E. Gómez-Martín, and A. Corredor. 2011. Armor unit placement, randomness and porosity of cube and Cubipod armor layers. International Conference on Coastal Structures 2011, ASCE, B9-067 (in press).

Pardo, V., J. Molines, and J.R. Medina. 2010. Experimental Analysis of the Influence of Armor Unit Placement Method on Armor Porosity. Proc. $3^{\text {rd }}$ International Conference on the Application of Physical Modelling to Port and Coastal Protection, 25.1-25.10.

SPM. 1984. Shore Protection Manual. U.S. Army Corps of Engineers, Waterways Experiment Station, Coastal and Hydraulics Laboratory, Vicksburg, MS.

Van der Meer, J. 1999. Design of concrete armour layers. Proceedings of the Coastal Structures '99. A.A. Balkema, 213-221.

Yagci, O., and S. Kapdasli. 2003. Alternative placement technique for antifer blocks used on breakwaters. Ocean Engineering, 30, 1433-1451. 